\title{
Correspondence
}

\section{The Calman Report on specialist training}

Sir: My inclination is to side with Dr Kisely (Psychiatric Bulletin, May 1994, 18, 309) against the CTC's response to the Calman Report as expressed by Dr Davies (Psychiatric Bulletin, May 1994, 18, 308-309) and I would question whether the CTC view is really representative of trainees.

The College proposal to downgrade the registrar grade to SHO and to call the senior registrar grade the unified training grade (UTG) gives a clear message to trainees that they should carry on as before for less money. The Calman proposal to combine registrar and senior registrar grades could immediately abolish the postmembership registrar bottleneck, to the relief of trainees demoralised by the competition for senior registrar posts immediately after the trials of the MRCPsych examination.

Moreover, the Calman plans to shorten the length of training must benefit psychiatry because of the number of unfilled consultant posts. The College plans may make psychiatry less attractive compared to other specialities, at a time when there is some evidence that recruitment to psychiatry is falling.

Combining the SHO and registrar grade could make the period of general professional/basic specialist training too long. What are the entry requirements to UTG going to be and will there be a link with MRCPsych? How many SHOs and UTGs does the College think are needed?

Although the privileges of senior registrars have been hard-earned. I think we have got the balance between higher and junior trainees wrong. We should be protecting the less experienced trainees from taking on service reponsibilities. I can understand why senior registrars want to stay in their posts longer than they should before accepting the realities of consultant work but such a system does not help to fill vacant consultant posts and pull through the backlog of post-membership registrars.

My hope is that the CTC and other College committees will seriously consider whether psychiatric training can be further improved in the light of the Calman Report rather than following the President's "conservative" lead.

D.B. Double, Sheffield Postgraduate Psychiatric Education, Northern General Psychiatric Unit, Sheffield S5 7AU
Sir: I am sorry to say that Dr Double misrepresents "the College proposal" in relation to the Calman Report.

There has been no suggestion in any College document or statement that we should "down grade the registrar grade to SHO". All specialities will be required to move to two training grades within the timetable which is agreed.

Trainees in psychiatry will have the same terms and conditions of service as those in other specialities, and the grades will provide a structured training programme from registration to CCST as is required.

The terms and conditions of service of the two grades have not yet been discussed and there is no proposal of which I am aware that trainees should "carry on as before for less money"; why on earth should they?

We expect in the setting of numbers to be trained in the two grades to "immediately abolish the post membership registrar bottle-neck" and I should be grateful if $\mathrm{Dr}$ Double could indicate how, under his proposal, we would be able to identify those trainees who are suitable for higher specialist training in one of the six psychiatric specialities (and how would they?)

Our proposals under Calman will still involve specialist training which is shorter than that in many specialities, where the minimum length of higher specialist training will still be at least five years.

I should be interested in the criteria against which Dr Double is making the judgement that "the period of general professional/basic specialist training" is too long. That has not been the perception of any group of individuals within the College since the Calman proposals have been debated. Should we shorten the training deemed essential for specialist practice in psychiatry because we currently have a manpower problem (and moreover one that is not of our making)?

The entry requirements to the UTG will be agreed by the College and the JCHPT when the proposals for the grade have been decided between the profession and the NHSE, though I am sure that there will be a connection with the MRCPsych. (As I write the last meeting on the UTG working groups is about to occur).

In terms of planning the numbers of doctors required in each training grade, the College will continue to relate this to consultant opportunities but in any event the planning and monitoring of training grade numbers are currently being streamlined by the NHSE. 
I can sympathise with Dr Double's point about protecting less experienced trainees from inappropriate service responsibilities and trust that we will be even better at doing so when postgraduate medical training is more protected within the NHS, and the service staffed with appropriately trained people in order that this can occur, as Achieving a Balance and 'Calman' require.

Is recruitment to psychiatry falling, or are we being affected by the devastating drop in recruitment to general practice?

Finally, I find Dr Double's labelling of me as "conservative" ironic.

F. CAldicotT, President, Royal College of Psychiatrists

Sir: It is unfortunate that the debate about improving psychiatric training in response to Calman has cencentrated on where exactly the split between basic and higher specialist training should occur and when exactly to award the CCST. This had obscured discussion about how to improve the quality of psychiatric training, which is far more important than what we call trainees for how long. Debate at the latest CTC meeting attempted to address issues such as content of training; setting training goals; educational contracts; methods of assessment; feedback and progress reviews; the role of research; flexible training. Calman's proposals for structured training were intended to address much more than just the structure of the training grades - a fact we would all do well to remember.

STEFFAN DAVIES, Chairman, Collegiate Trainees Committee, Royal College of Psychiatrists

Sir: Evans \& Johnson (Psychiatric Bulletin, July 1994, 18, 405-407) cite two possible models for the delivery of medical care: an elite body of consultants with a small group of trainees (most of the clinical work being undertaken by nonconsultant career grades), and a large body of consultants with increased clinical care. The Calman Report seems to aim towards the second model. However, while its recommendations have been accepted by the government, no extra funding has been set aside to implement them. This, coupled with the Health Minister's intention to ease restrictions on numbers of SHOs and staff grade doctors, suggests that we are in reality moving towards the first model.

The paper reports that $69 \%$ of the senior registrars were not in favour of a new NHS subconsultant grade. Presumably they see themselves being promoted to the first model's "elite body of consultants", rather than filling the non-consultant career grades. However, in all probability a significant proportion will become caught in the post-CCST (Certificate of Completion of Specialist Training) gap, exposed to the potential for exploitation as cheap labour by NHS trusts.

Rather than resign ourselves to the inevitability of a sub-consultant grade introduced through the back door, we might do better to embrace the opportunity to develop a new specialist grade. This could meet many of the needs created by the complex changes occurring within health care. A period of independent clinical practice postmembership would meet some of the increased service needs created by reducing juniors' hours while addressing the expectation that an increasing proportion of patients will be treated by trained specialists. If such posts allowed progression to consultant status they would not be seen as 'dead end' jobs but as a period where further experience and skills could be developed. This period could have fewer of the management and non-clinical responsibilities of consultants, and be of variable length to give greater security while allowing the necessary flexibility to meet the needs of individuals. Surely it is better to negotiate suitable terms and conditions for a specialist post now, rather than let ourselves be shunted into an inferior sub-consultant post by default.

DAVID ROBERTSON, Department of Psychiatry, University of Leicester, Leicester General Hospital, Leicester LE5 4PW

\section{Care programme approach}

Sir: Nigel Fisher's (Psychiatric Bulletin, August 1994, 18, 453-456) valuable editorial on community care may have been too charitable about the confusion of the political and clinical in policy. The imposition of the care programme approach (CPA) without a clear understanding of its impact has been wasteful for mental health services. I think trusts and districts are likely to remain confused despite the recent guidance on discharge and continuing care.

The essential problem has been in deciding to whom the CPA applies. There are also questions about the value of bureaucratising the care planning process. I am not convinced the Department of Health (DH) has fully considered these issues. The $\mathrm{DH}$ seems to have believed that it has exercised its responsibility by merely requiring the implementation of the CPA. Mental health services have not been blameless in this respect as they have not been very forthcoming in reporting difficulties in implementing the approach. 